\section{An unusual cause of right heart failure}

\author{
Paul Hill, ${ }^{1}$ Jagdip Sidhu, ${ }^{2}$ \\ Rachel Bastiaenen ${ }^{1}$ \\ ${ }^{1}$ Guys and St Thomas NHS Trust, \\ London; ${ }^{2}$ Darent Valley Hospital, \\ Darent, UK
}

\begin{abstract}
Carcinoid syndrome is a paraneoplastic condition, which usually affects the lungs or gastrointestinal tract but uncommonly cardiac valves can be involved, causing carcinoid heart disease. We describe a case of a 60 -year-old man presented with a twelve-month history of worsening shortness of breath and decreased exercise tolerance. Investigations confirmed grade 1 metastatic neuroendocrine carcinoma (carcinoid tumour) of likely gastrointestinal tract origin. Two months after diagnosis he underwent successful tricuspid valve replacement and pulmonary root replacement. Cytoreductive surgery of the right lobe of the liver and the ileal primary is planned. Cardiac surgery is the only definitive treatment for carcinoid heart disease and should be considered in all those with symptoms and evidence of severe valvular disease.
\end{abstract}

\section{Brief Report}

A 60-year-old man presented with a twelve-month history of worsening shortness of breath and decreased exercise tolerance. For six months, there had been associated leg swelling, hot flushes and loose stools (up to 12 times per day). His past medical history included hypertension and dyslipidaemia. His medications were amiloride, spironolactone, nifedipine, enalapril and atorvastatin. He worked in a water treatment plant, was a non-smoker and drank 16-20 units of alcohol per week. Initial blood results were unremarkable (Table 1).

A transthoracic echocardiogram (TTE) demonstrated severe right ventricular (RV) dilatation (basal diameter $68 \mathrm{~mm}$, RV length $81 \mathrm{~mm}$ ) with normal systolic function (Figure 1A). The left ventricular cavity was small with normal systolic function (LV ejection fraction 55-60\%). There was flattening of the septum during diastole consistent with RV pressure overload (Figure 1B). The right atrium was severely dilated (area $41 \mathrm{~cm}^{2}$ ). The tricuspid valve leaflets were thickened and restricted with loss of coaptation (Figure 1C). As a result, there was severe tricuspid regurgitation with a triangular pattern of the Doppler profile (Figure 1D) and flow reversal in the hepatic vein. The pulmonary valve leaflets were thickened (Figure 2) with increased gradient across the valve (mean gradient $8.5 \mathrm{mmHg}$ ). Following admission, he was treated with intravenous diuretics.

Magnetic resonance imaging detected a $13.5 \mathrm{~cm}$ liver lesion (Figure 3), caecal thickening and extensive ascites. Positron emission tomography-computed tomography (PET-CT) using a Gallium-68 labelled somatostatin analogue localized multiple liver lesions with intense tracer uptake, compatible with neuroendocrine metastases (Figure 4). There was intense increased tracer uptake in a focal segment of the ileum, suspicious for a primary neuroendocrine small bowel tumor (Figure 4).

Liver biopsy confirmed grade 1 metastatic neuroendocrine carcinoma (carcinoid tumour) of likely gastrointestinal tract origin. He was started on octreotide which was changed to sandostatin and cyproheptadine. His bowel symptoms and flushing started to improve. Two months after diagnosis he underwent successful tricuspid valve replacement and pul-
Correspondence: Paul Hill, Guys and St Thomas NHS Trust, Westminster Bridge Road, London, SE1 7EH, UK.

E-mail:paul.hill3@nhs.net

Key words: Carcinoid; heart failure; neuroendocrine; tricuspid regurgitation; pulmonary stenosis.

Acknowledgements: David Murphy, Radiology SpR, Guys and St Thomas NHS Trust, Jenna Smith, Cardiac Physiologist, Guys and St Thomas NHS Trust.

Contributions: PH, RB, written and edited; JS, edited and reviewed.

Received for publication: 14 April 2018.

Revision received: 10 March 2019.

Accepted for publication: 20 May 2019.

This work is licensed under a Creative Commons Attribution NonCommercial 4.0 License (CC BY-NC 4.0).

(C) Copyright P. Hill et al., 2019

Licensee PAGEPress, Italy

Cardiogenetics 2019; 9:7503

doi:10.4081/cardiogenetics.2019.7503

monary root replacement. Cytoreductive surgery of the right lobe of the liver and the ileal primary is planned.

Table 1. Primary blood results.

\begin{tabular}{lcc} 
Test & Result & Normal range \\
Haemoglobin & 153 & $(130-170) \mathrm{g} / \mathrm{L}$ \\
White blood count & 8.0 & $(4.0-11.0) \times 10^{9}$ \\
\hline Platelets & 195 & $(150-400) \times 10^{9}$ \\
C reactive protein & 7 & $(0-4) \mathrm{mg} / \mathrm{L}$ \\
\hline Estimated glomerular filtration rate & 39 & $(70-130) \mathrm{mL} / \mathrm{min}$ \\
Bilirubin & 21 & $(0-21) \mathrm{umol} / \mathrm{L}$ \\
\hline Alt & 27 & $(4-59) \mathrm{IU} / \mathrm{L}$ \\
ALP & 194 & $(35-129) \mathrm{IU} / \mathrm{L}$ \\
\hline Albumin & 42 & $(40-52) \mathrm{g} / \mathrm{L}$ \\
Corrected calcium & 2.43 & $(2.15-2.55) \mathrm{mmol} / \mathrm{L}$ \\
\hline Immunoglobulin A & $5.91($ slightly raised) & $(0.8-4.0) \mathrm{g} / \mathrm{L}$ \\
Serum protein electrophoresis & No paraprotein band & - \\
\hline CEA, CA19-9, auto-immune screen & Normal & - \\
Hepatitis serology & Normal & $(0-35) \mathrm{kU} / \mathrm{L}$ \\
\hline Urine 5-HIAA & $1182 \mu \mathrm{mol} / \mathrm{L}$ & $<50 \mu \mathrm{mol} / \mathrm{L}$ \\
Urine 5-HIAA & $713 \mu \mathrm{mol} / \mathrm{L}$ & $<50 \mu \mathrm{mol} / \mathrm{L}$ \\
\hline
\end{tabular}




\section{Discussion and Conclusions}

Carcinoid syndrome is a paraneoplastic condition, which usually affects the lungs or gastrointestinal tract but uncommonly cardiac valves can be involved, causing carcinoid heart disease. Carcinoid syndrome is rare, with an approximate incidence of $1.2-2.1$ per 100,000 of the general population. ${ }^{1}$ Patients present with shortness of breath, diarrhoea, wheeze and facial flushing. These classic symptoms are attributed to the release of polypeptides, biogenic amines and prostaglandins secreted by carcinoid tumours. These include serotonin (5-HT), dopamine, histamine, bradykinin, chromogranin A. ${ }^{2}$

At a molecular level, neuroendocrine tumour (NET) growth is poorly understood. Genetic syndromes including Von Hippel Lindau syndrome and neurofibromatosis may be associated with gastrointestinal NETs. ${ }^{2,3}$

Diagnosis of carcinoid syndrome is based on clinical symptoms, $24 \mathrm{~h}$ urinary 5-HIAA collection, serum chromogranins (including $\mathrm{A}, \mathrm{B}$ and $\mathrm{C}$ ) and imaging using MRI or PET-CT scanning with radiolabelled somatostatin analogues. PET-CT scanning using these methods has been shown to improve detection and staging of neuro-endocrine tumours. ${ }^{4}$

Carcinoid heart disease usually manifests as thickening of the endocardium of the right heart, the left heart is spared due to inactivation of 5-HT by the lungs. ${ }^{5}$ The thickening is due to plaque-like fibrous deposits, which can adhere to any area of endocardium including the valvular cusps, papillary muscles and cardiac chambers.

TTE should be the first line investigation in those suspected of having carcinoid heart disease. This may show thickening of either the tricuspid or pulmonary valve with consequent stenosis or regurgitation. Long standing disease results in progressively raised right heart diastolic pressures and failure. TTE should also be considered in those undergoing surgery for resection of carcinoid disease in lung, liver or bowel. This is because of the potential increased risk of bleeding in those with raised right sided pulmonary pressures.

Cardiac surgery is the only definitive treatment for carcinoid heart disease and should be considered in all those with symptoms and evidence of severe valvular disease. ${ }^{6}$ Medical treatment includes the use of somatostatin analogues (e.g. octeotride and lanreotide), which bind to the tumour receptors and prevent the release of hormones into the circulation, relieving patients of their symptoms.

Median survival following the onset of

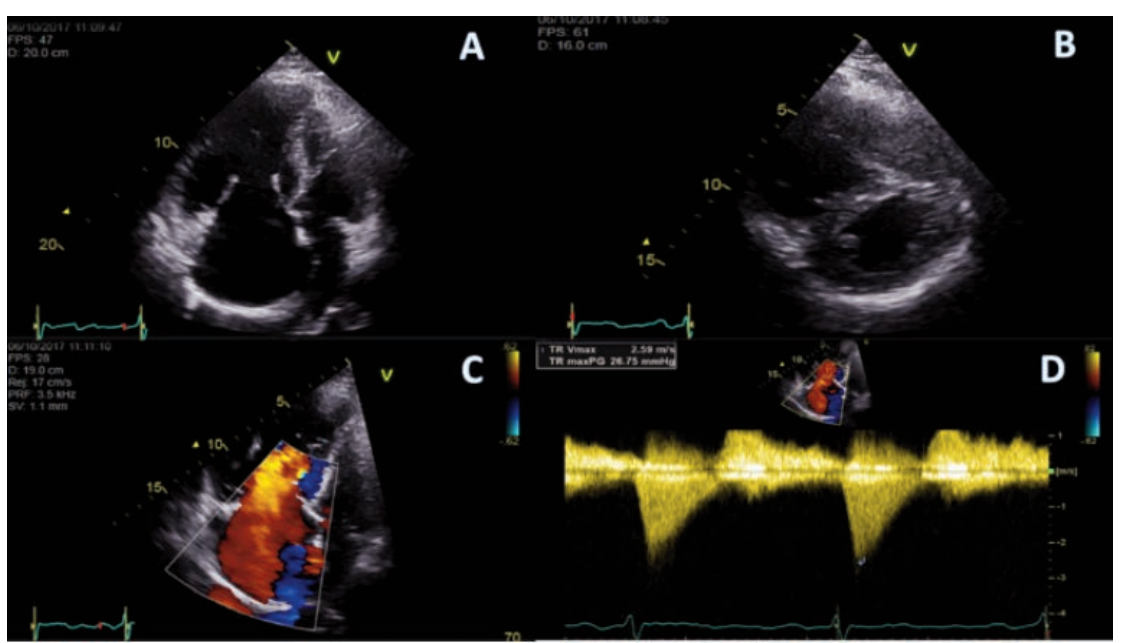

Figure 1. A) Dilated right ventricle on apical 2 chamber view; B) Flattening of left ventricular septum in diastole on parasternal short axis view; C) Severe tricuspid regurgitation on apical 2 chamber view with colour Doppler; D) Triangular pattern of tricuspid regurgitation on pulse wave Doppler.

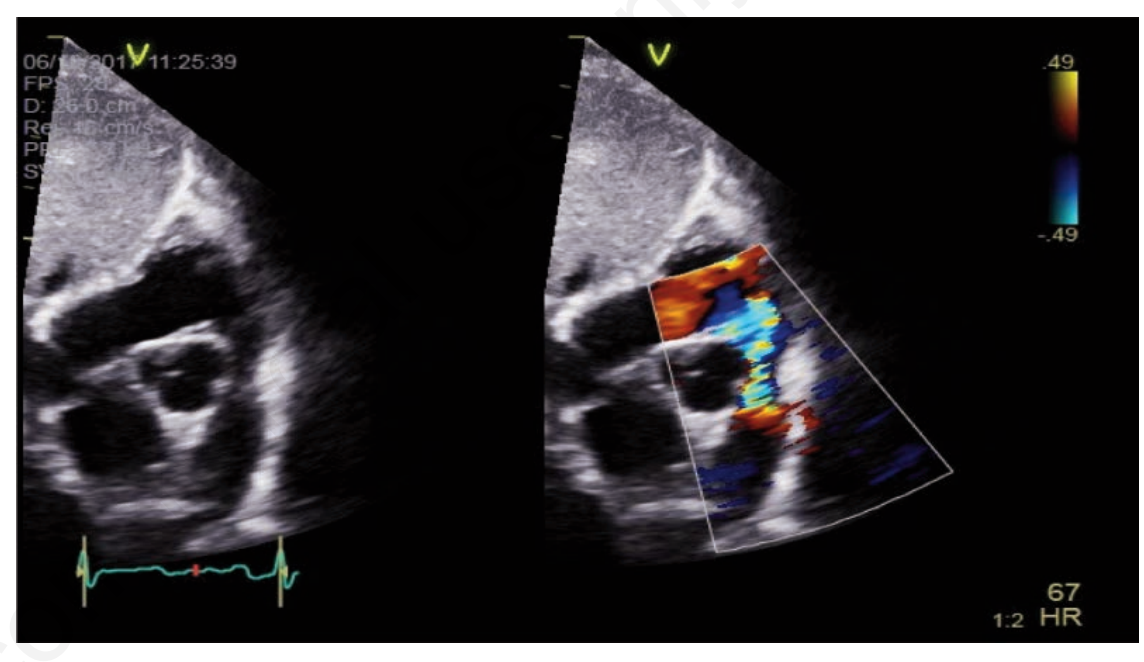

Figure 2. Echocardiography demonstrates thickened pulmonary valve leaflets and pulmonary stenosis (subcostal short axis view).

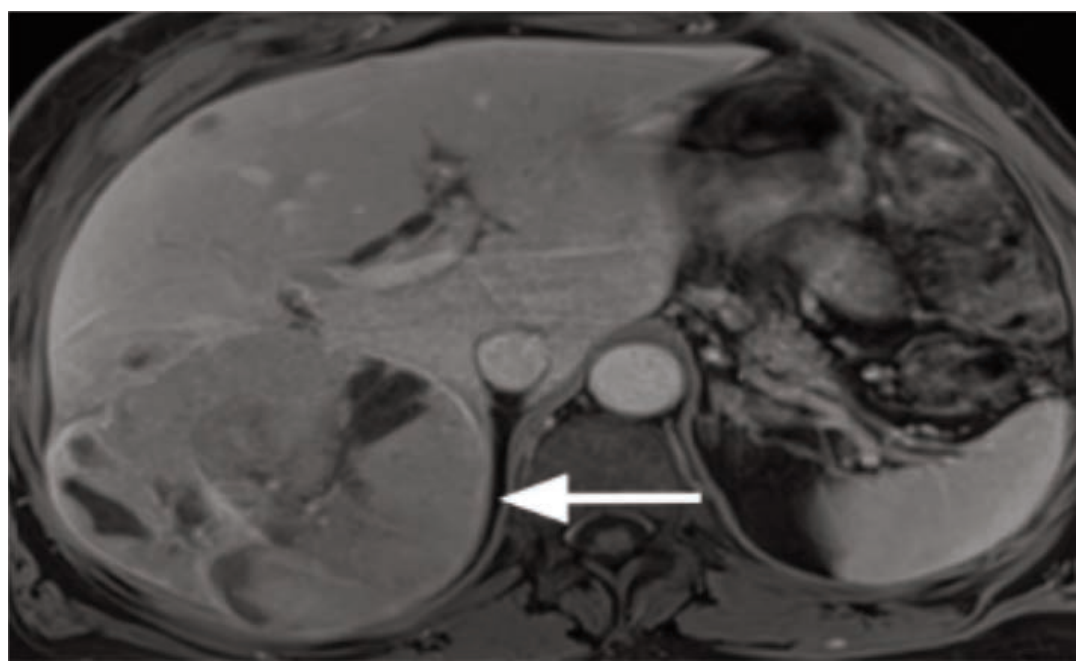

Figure 3. Magnetic resonance imaging axial T1 Dixon water post gadolinium image shows a large, heterogeneously enhancing mass (arrow) in the right lobe of the liver with central necrosis. 


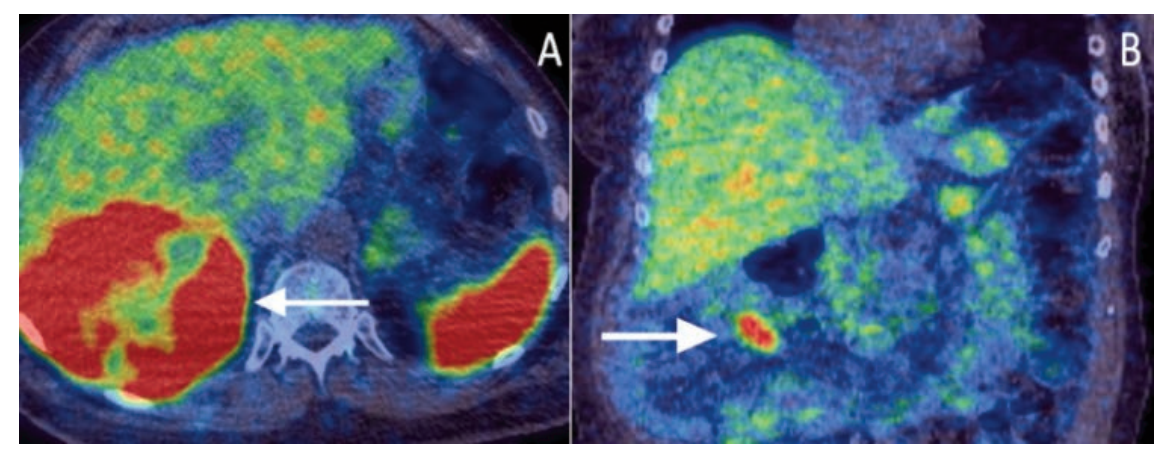

Figure 4. A) Fused Ga68-DOTATATE PET/CT imaging demonstrates corresponding intense tracer uptake in the liver mass (arrow) with central photopaenia (axial image panel A); and B) focal intense tracer uptake in a small bowel loop (arrow) in the right lower quadrant (coronal image panel B).

symptoms of 4.8 years has been demonstrated in one retrospective study of 200 patients post cardiac surgery. ${ }^{7}$

1. Modlin IM, Sandor A. An analysis of noids.

Gastroenterology

2005; $128: 1717$.

3. Ramage JK, Goretzki PE, Manfredi R, et al. Consensus guidelines for the management of patients with digestive neuroendocrine tumours: well-differentiated colon and rectum tumour/carcinoma. Neuroendocrinology 2008;87:31-9.

4. Sadowski SM, Neychev V, Milo C, et al. Prospective study of $68 \mathrm{Ga}-$ DOTATATE positron emission tomography/computed tomography for detecting gastro-entero-pancreatic neuroendocrine tumors and unknown primary sites. J Clin Oncol 2016;34:588.

5. Gray H, Dawkins K, Morgan J, Simpson IA. Lecture notes in cardiology, 4th Ed. Oxford: Blackwell Science Company; 2006. Ch 12, pp 194-195.

6. Connolly HM, Schaff HV, Abel MD, et al. Early and late outcomes of surgical treatment in carcinoid heart disease. J Am Coll Cardiol 2015;66:2189. 8305 cases of carcinoid tumors. Cancer 1997;79:813.

2. Modlin IM, Kidd M, Latich I, et al. Current status of gastrointestinal carci-
7. Moller JE, Pellikka PA, Bernheim AM, et al. Prognosis of carcinoid heart disease: analysis of 200 cases over two decades. Circulation 2005;112:3320. 